\title{
High prevalence of Schistosoma mansoni and other intestinal parasites among elementary school children in Southwest Ethiopia: a cross-sectional study
}

\author{
Ayalew Jejaw ${ }^{1 *}$, Endalew Zemene ${ }^{2}$, Yayehirad Alemu$^{1}$ and Zemenu Mengistie ${ }^{1}$
}

\begin{abstract}
Background: Intestinal parasitic infections (IPIs) pose significant public health challenges in school children in developing countries. The aim of this study is to determine prevalence of intestinal parasites among elementary school children in Mizan-Aman town, southwest Ethiopia.

Methods: Institution-based cross-sectional study involving 460 elementary school children in Mizan-Aman Town was conducted from May to June 2013. The school children were selected using multistage sampling technique. Data on demography and predisposing factors of IPIs were collected using pretested questionnaire. Moreover, single stool specimen was examined microscopically after wet mount and formol-ether sedimentation concentration procedures. Infection intensity of Schistosoma mansoni and soil-transmitted helminths (STHs) was estimated using Kato-Katz egg counting method.
\end{abstract}

Results: Age of the children ranged from 5 to 17 years. Overall, $76.7 \%$ (95\%Cl: $72.8-80.6)$ of the children harbored at least one species of intestinal parasite. Eight species of intestinal parasites were detected with S. mansoni (44.8\%) and Ascaris lumbricoides (28.7\%) being predominant. Helminths and pathogenic intestinal protozoa were detected in 73.9 and $7.8 \%$ of the children, respectively. After adjusting for other variables, age between 5 and 9 years $(\mathrm{AOR}, 2.6,95 \% \mathrm{Cl}$, 1.552-4.298), male gender (AOR, 2.1,95\%Cl, 1.222-3.526), attending public school (AOR, 0.1, 95\%Cl, 0.060-0.256), using river/well water (AOR, $2.4,95 \% \mathrm{Cl}, 0.912-6.191)$, irregular washing of hands before meal (AOR, $0.5,95 \% \mathrm{Cl}, 0.254-0.865)$, consuming street food $(A O R, 2.3,95 \% \mathrm{Cl}, 1.341-3.813)$ and raw vegetables (AOR, 2.7, 95\%Cl, 1.594-4.540) were significantly associated with IPIs in the study participants.

Conclusion: Prevalence of intestinal parasites among the school children was high. Deworming of the school children and continuous follow up is required.

Keywords: S. mansoni, Intestinal parasites, School children, Ethiopia

\section{Background}

Intestinal parasitic infections (IPIs) are the most common infections in developing countries, where sanitary facilities are scarce. Globally, the three most common soil-transmitted helminths (STHs) Ascaris lumbricoides, Trichuris trichiura and the anthropophilic hookworms (Ancylostoma duodenale and Necator americanus) are

\footnotetext{
* Correspondence: ayalewjejaw@yahoo.com

${ }^{1}$ Department of Biomedical Science, College of Health Sciences, Mizan-Tepi University, Mizan, Ethiopia

Full list of author information is available at the end of the article
}

responsible for majority of the disease burden due to neglected tropical diseases. It is estimated that 819.0, 464.6 and 438.9 million people are infected with A. lumbricoides, T. trichiura and the hookworms, respectively [1]. Schistosomes affect an estimated 240 million people worldwide, with the risk in Africa commonly associated with development of water resources [2]. While the parasites may infect people of all ages in impoverished communities, children are more likely to get infected.

Young children and individuals with heavy worm burden suffer the most from morbidity associated with the 
STH and S. mansoni infections. Although mortality due to these infections is rare, the morbidity and detrimental effects on socio-economic development resulting from these infections is enormous [3-7]. Apart from the direct health impacts, malaria-helminth co-infections may also increase severity of malarial anemia resulting in gametocyte carriage, perhaps affecting transmission dynamics of malaria in endemic areas [8].

Deworming of helminth infected children is required to reduce the nutritional deficit resulting from these infections $[9,10]$. The World Health Organization (WHO) recommends mass school-based deworming of schoolage children twice a year if prevalence of the STHs $\geq$ $50 \%$, and once every year if the prevalence is $\geq 20 \%$ and less than $50 \%$ [11].

Baseline surveys of IPIs produce essential evidence to take appropriate interventions, particularly for control of STHs and Schistosoma infections. Most of the epidemiological studies of intestinal parasites carried out in Ethiopia documented often high prevalence of intestinal parasites among school children, with the STHs being most predominant [12, 13]. School-age children in developing countries, including Ethiopia, are typically at increased risk of IPIs as a result prevailing predisposing factors $[14,15]$. Despite these, no published report on the magnitude of IPIs among elementary school children in Mizan-Aman Town was obtained. This research is, therefore, initiated with the objective of determining prevalence of intestinal parasites among school children enrolled in elementary schools in the town.

\section{Methods}

\section{Study setting}

The study was conducted in Mizan-Aman Town from May to June, 2013. Mizan-Aman Town is found in Bench Maji Zone of the Southern Nations, Nationalities and Peoples' Region of Ethiopia (Fig. 1). The town is located $550 \mathrm{kms}$ southwest of the capital Addis Ababa. The area is characterized by warm climate (mean annual temperature ranges between 15.1 and $27^{\circ} \mathrm{C}$ ), perennial rivers, and is considered ideal for agriculture and human settlement. The mean annual rainfall ranges from 400 to $2000 \mathrm{~mm}$. The major economic activity of the urban inhabitants is trading while subsistence farming is the dominant means of earning a living for the surrounding rural population. In the year 2013, a total of 18 elementary schools (11 public and 7 private) were present in the town. A total of 14,393 children were enrolled in the elementary schools in the town in the year 2014.

\section{Study design and sample size determination}

School-based cross-sectional study was conducted. Sample size was determined using single population proportion formula $n=\mathrm{Z}^{2} \mathrm{p}$ (1-p) / $\mathrm{d}^{2}$, with the following assumptions: prevalence (p) of $83.8 \%$ from a previous

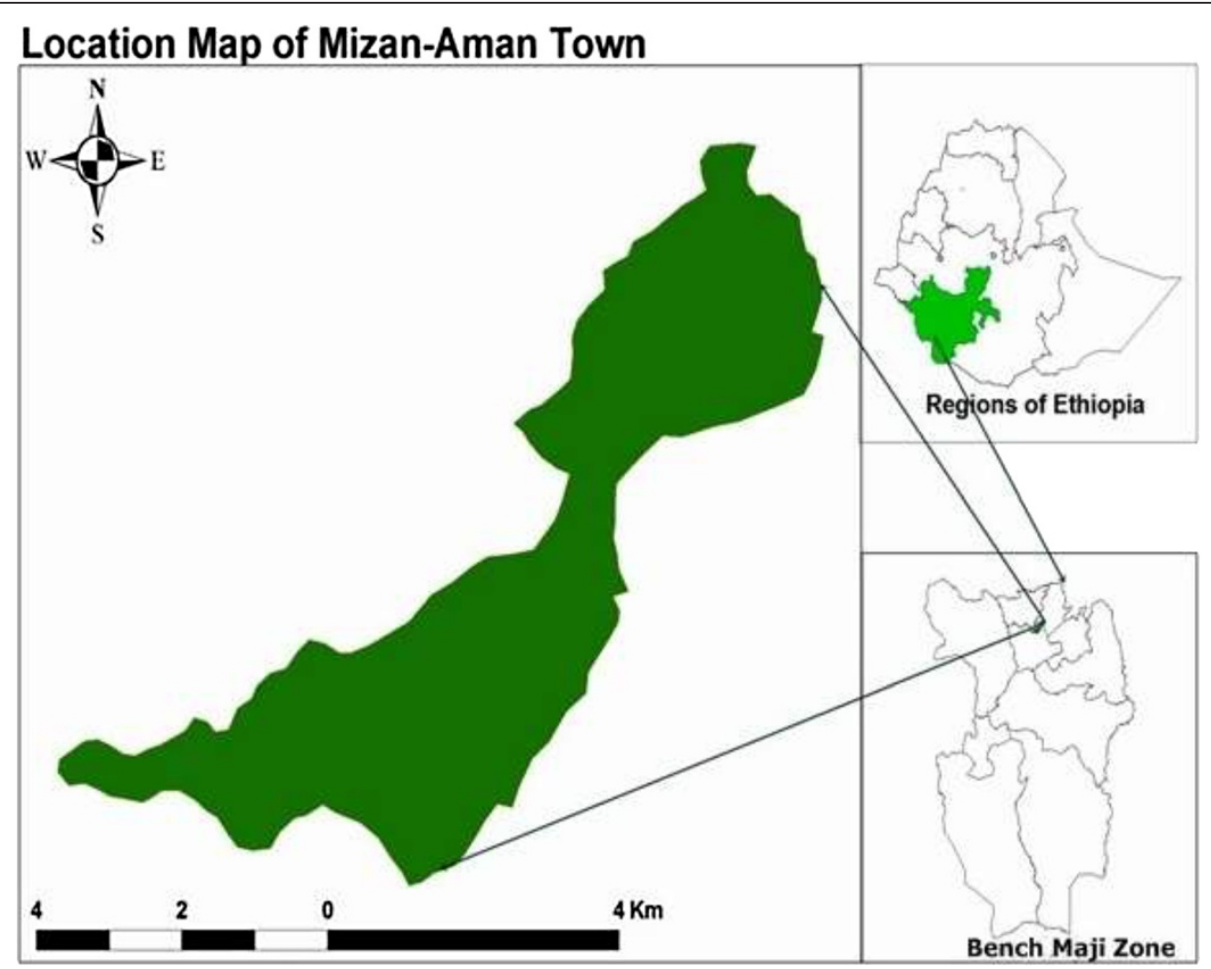

Fig. 1 Map of the study area 
study [16], $95 \%$ confidence level, $5 \%$ margin of error, design effect of 2 and $10 \%$ for anticipated non-response rate. Accordingly, the minimum sample size (n) was found to be 460 school children.

Multistage sampling was employed to select the study participants. First, seven of the elementary schools were randomly selected by lottery method. The sample size was allocated to the selected elementary schools proportional to the total number of student population in each of the schools. Accordingly, 145, 144, 63, 60, 31, 10 and 7 school children were sampled from Mizan Number One, Aman, Ediget Behibret, Gacheb, Mizan Misgana Academy, Aman Misgana Academy and Abune Teklehaymanot elementary schools, respectively. The school children were selected by systematic sampling technique, using list of the students as sampling frame. Children attending school in the selected elementary schools during the study period, who were voluntary to participate in the study and able to provide stool sample within the study period were included in this study.

\section{Demographic and personal risk factors survey}

Data on demographic profile of the children and factors predisposing to IPIs was gathered using pretested questionnaire. The questions included information on gender, age, shoe wearing pattern, source of drinking water, bathing in the river, habit of eating raw vegetables and street foods among others. Trained nurses who were fluent with the local languages (Amharic and Bench) interviewed the study participants.

\section{Parasitological examination}

Single stool specimen was collected from each study participant using clean plastic container labeled with unique identification number. The children were instructed on how to provide at least a thumb-sized stool specimen of their own, avoiding contamination with urine. The specimens were collected at each school and immediately transported to Clinical Laboratory of Mizan-Tepi University for processing. Direct wet smear using physiological saline and Lugol's iodine was done. Portion of the stool samples were processed by formol-ether sedimentation concentration technique, and examined microscopically following standard procedure [17]. Moreover, infection intensity of STHs and S. mansoni was determined using Kato-Katz technique. A single Kato-Katz slide was processed for each stool specimen. The specimens were processed on the same day of collection. Results of the laboratory investigation were recorded on a format prepared for this purpose.

\section{Data analysis}

Infection intensity of the STHs and S. mansoni was estimated by multiplying the total number of eggs counted by 24 , which gives as the eggs per gram (epg) of stool.
Infection intensities of S. mansoni and the STHs were classified as light, moderate and heavy per the threshold set by WHO $[18,19]$. The collected data were checked for completeness, entered into computer, and analyzed using SPSS version 20.0 software package. Descriptive statistics were used to summarize demographic profile of the study participants. Bivariate and multivariable logistic regression procedures were employed to identify factors associated with IPIs in the study participants. Variables appearing significantly associated with IPI by the bivariate analysis, and other biologically plausible variables were candidates for the multivariable model. The multivariable model was fitted by backward elimination technique. Statistical significance was set at $\mathrm{p}$ value $<0.05$.

\section{Ethical clearance}

Ethical clearance was obtained from the Institute of Research and Community Support of Mizan-Tepi University. Permission was sought from Mizan-Aman Town Education and Health Offices. Informed verbal consent was obtained from the students and directors of each school. Parent/guardian consent was obtained for minors to participate in the study. Laboratory results were kept confidential. Students with positive results for intestinal parasite(s) were treated in collaboration with the health centres in the town.

\section{Results}

\section{Characteristics of the study participants}

Table 1 shows demographic characteristics of the study participants. A total of 460 school children $(50.4 \%$ female and $49.6 \%$ male) participated in the study. Age of the children ranged from 5 to 17 years (mean age 9.1 years). Most of the children (64.1\%) were within the age group 5-9 years.

Table 1 Demographic characteristics and intestinal parasitic infection among the school children, Mizan-Aman Town, 2013

\begin{tabular}{llll}
\hline $\begin{array}{l}\text { Demographic } \\
\text { characteristics }\end{array}$ & \multicolumn{2}{l}{ Intestinal parasite } & Total \\
\cline { 2 - 3 } & Positive n(\%) & Negative $\mathrm{n}(\%)$ & \\
\hline Gender & & & \\
Male & $190(83.3)$ & $38(16.7)$ & $228(49.6)$ \\
Female & $163(70.3)$ & $69(29.7)$ & $232(50.4)$ \\
Age group (years) & & & \\
5-9 & $242(82.0)$ & $53(18.0)$ & $295(64.1)$ \\
$\geq 10$ & $111(67.3)$ & $54(32.7)$ & $165(35.9)$ \\
Type of school & & & $412(89.6)$ \\
Public & $336(81.6)$ & $76(18.4)$ & $48(10.4)$ \\
Private & $17(35.4)$ & $31(64.6)$ &
\end{tabular}




\section{Prevalence of intestinal parasites and associated risk factors}

At least one species of intestinal parasite was detected in $76.7 \%$ (95\%CI: 72.8-80.6) of the children. Eight species of intestinal parasites were identified. S. mansoni was the most common intestinal parasite detected (44.8\%), followed by $A$. lumbricoides (28.7 \%). Prevalence of each intestinal parasite is demonstrated in Fig. 2.

Out of the total children, 340 (73.9 \%) were positive for at least one species of intestinal helminth, and 36 (7.8 \%) were positive for protozoan parasites (Giardia lamblia and Entamoeba histolytica/dispar/moshkovskii). Risk factors associated with helminth infections include consumption of undercooked/raw vegetables (AOR 2.8, 95\%CI, 1.705-4.889), consumption of street food (AOR 2.5, 95\%CI, 1.523-4.368), male gender (AOR, 2.3, 95\%CI, 1.392-4.043), age less than ten years (AOR 3.2, 95\%CI, 1.880-5.498), being enrolled in public elementary school (AOR 0.095, 95\%CI, 0.043-0.212), using river water for drinking (AOR 4.385, 95\%CI, 2.504-7.679). Two hundred and sixty nine $(58.5 \%)$ of the children responded to bath and wash clothes in the river. Prevalence of S. mansoni among these children (64\%) was significantly higher than those who responded not taking bath and washing clothes in the river (data not presented).

Prevalence of intestinal parasites among the school children in each school included in the study is presented in Table 2. There was a significant difference in prevalence of intestinal parasites in the children among the schools $(p<0.001)$. Moreover, prevalence of intestinal parasites among the school children enrolled in public elementary schools (84.1\%) was significantly higher than those enrolled in private schools (35.4\%) $(p<0.001)$. Multiple IPIs were detected in $35.4 \%$ of the infected children. S. mansoni/A. lumbricoides double infections (47\%) and S. mansoni/A. lumbricoides/T. trichiura triple infections (34\%) were the most commonly encountered multiple infections.

Infection intensity of S. mansoni and the STHs detected in this study is shown in Table 3. Most of the $S$. mansoni and T. trichiura infected children had moderate infection intensity. Heavy infection with S. mansoni, A. lumbricoides and T. trichiura was obtained 4.4, 5.3 and $3.5 \%$ of the children infected with each of the parasites, respectively.

Independent risk factors associated with IPI among the school children is presented in Table 4. After adjusting for other variables, male gender (AOR 2.1, 95\%CI, 1.222-3.526), age group within 5-9 years (AOR 2.6, 95\%CI, 1.552-4.298), attending public school (AOR 0.1, 95\%CI, 0.060-0.256), using well/river as source of water supply (AOR 2.4, 95\%CI, 0.912-6.191), irregular washing of hands before meal (AOR 0.5, 95\%CI, 0.254-0.865), habit of eating raw vegetables (AOR 2.7, 95\%CI, 1.5944.540) and consumption of street foods (AOR 2.3, 95\%CI, 1.341-3.813) were significantly associated with IPI among the study participants.

\section{Discussion}

In this study, $76.7 \%$ of the children were positive for at least one species of intestinal parasite. Similarly high prevalence of intestinal parasites was reported among school children in Tikur Wuha [9], Zarima [13] and Lake Tana Basin [20] in northwest Ethiopia. However, the prevalence of intestinal parasites observed in this study is higher compared to similar studies done in Yadot primary school [21], Jimma zone [22] and Gondar

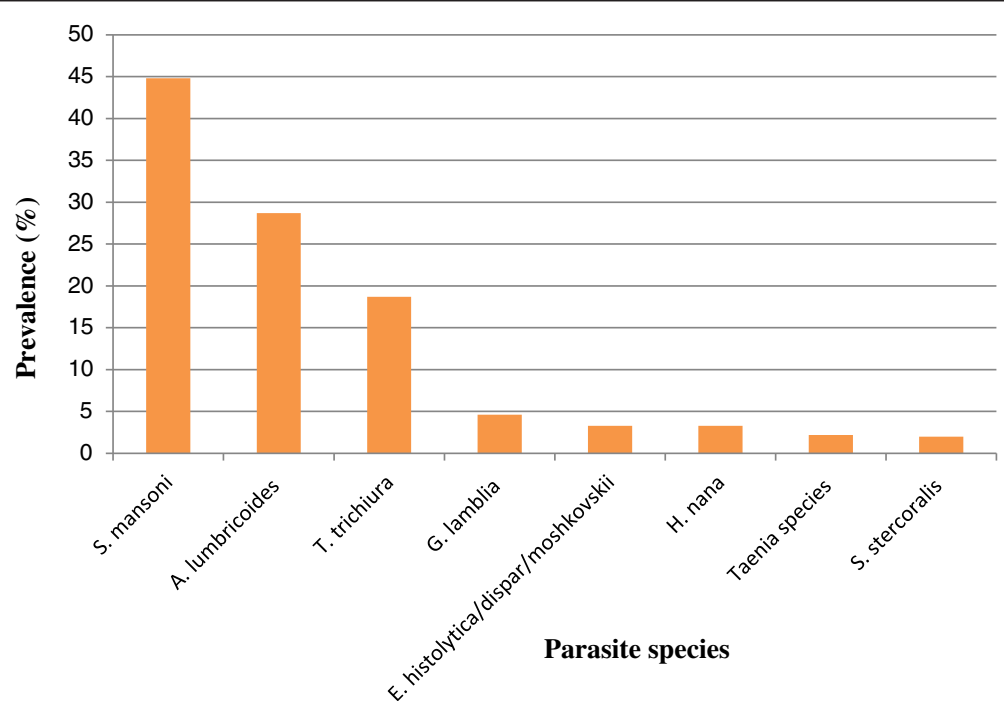

Fig. 2 Species distribution of intestinal parasites detected among the elementary school children in Mizan-Aman Town, 20013 
Table 2 Prevalence of intestinal parasites detected among the school children in each school, Mizan-Aman Town, 2013

\begin{tabular}{|c|c|c|c|}
\hline Name of the elementary school & $\begin{array}{l}\text { Number of } \\
\text { children } \\
\text { included }\end{array}$ & $\begin{array}{l}\text { Prevalence of } \\
\text { intestinal } \\
\text { parasite n(\%) }\end{array}$ & $95 \% \mathrm{Cl}$ \\
\hline Gacheb & 60 & $54(90.0)$ & $(82.4-97.6)$ \\
\hline Ediget Behibret & 63 & $56(88.9)$ & $(81.0-96.7)$ \\
\hline Mizan Number One & 145 & $121(83.4)$ & $(77.3-89.5)$ \\
\hline Aman & 144 & $105(72.9)$ & $(65.6-80.2)$ \\
\hline Abune Teklehaymanot ${ }^{a}$ & 7 & $3(42.9)$ & $(6.2-79.6)$ \\
\hline Mizan Misgana Academy ${ }^{a}$ & 31 & $11(35.5)$ & $(18.7-52.3)$ \\
\hline Aman Misgana Academy ${ }^{a}$ & 10 & $3(30.0)$ & $(1.6-58.4)$ \\
\hline Total & 460 & $353(76.7)$ & (72.8-80.6) \\
\hline
\end{tabular}

Cl Confidence interval

aPrivate schools

[23], in which prevalence of 26.2, 47.1 and $22.7 \%$ were reported, respectively. Difference in environmental and socio-economic factors may account for the variation in prevalence of intestinal parasites. The high prevalence of intestinal parasites obtained in this study necessitates regular deworming of the children.

In this study, $S$. mansoni was the most prevalent intestinal parasite encountered. In Ethiopia, activities involving river water including fishing, taking bath and swimming in the river, and washing of clothes and utensils using river water are common denominators for infection with $S$. mansoni $[12,24]$. In this study, it was also observed that prevalence of $S$. mansoni was significantly higher in children taking bath and washing clothes in the river. Snails of the genus Biomphalaria (B. sudanica and B. pfeifferi) are intermediate hosts of $S$. mansoni in Ethiopia [25, 26].

This study also revealed significantly higher prevalence of intestinal parasites among males and children aged 5-9 years. Male children usually play outdoors, and engage in outdoor activities compared to their female counterparts, which may predispose them to higher risks of IPI. Moreover, compared to females, male children are more likely to swim and take bath in the rivers, which might have contributed to the higher prevalence of S. mansoni observed among male children in this study. The higher prevalence of intestinal parasites in the younger children could be related to lack of awareness on transmission roots of intestinal parasites. Fentie and co-workers [20] also reported male gender as a risk factor for S. mansoni infection.

Fruits and vegetables may be contaminated with fecooral parasites. In this study, consumption of raw vegetables was significantly associated with IPI. Recently, Tefera et al. [27] reported parasite contamination in more than half of the fruits and vegetables collected from local markets in Jimma town. Consumption of street-food was also significantly associated with IPIs in this study, which could be due to unsafe food handling practices by the food vendors, and unhygienic environments where the foods are sold. Moreover, children who irregularly wash hands before meal, and those drinking well and river water were significantly more infected with intestinal parasites. The significant association of lack of pure water supply and unhygienic practices with IPIs was also documented by other investigators [13, 28, 29].

In this study, significantly higher prevalence of intestinal parasites was observed among children attending public schools compared to those attending private schools. The higher prevalence of intestinal parasites among the children attending public schools could be related to lower socio-economic status of their families. Association of lower-income family with higher risk of IPI in school children has been documented elsewhere [30].

Soil-transmitted helminth and schistosome infections are usually aggregated, with few proportions of individuals harboring the highest worm burden. In this study, majority of the children had moderate-to-heavy infection with the STHs and S. mansoni. Pre-school and schoolage children with moderate-to-heavy infection with STHs and S. mansoni suffer the most from health consequences of these infections [18, 31].

The major limitation of our study is that infection intensity of the STHs and S. mansoni was determined by examination of single stool specimen of each study participant. Moreover, a single Kato-Katz template was examined for each of the stool specimens. These might affect the accuracy of the egg count of the STHs and $S$. mansoni.

\section{Conclusions}

This study revealed high prevalence of intestinal parasites with $S$. mansoni being the most predominant. Demographic factors and hygienic practice of the school

Table 3 Infection intensity of S. mansoni and the STHs detected among the school children in Mizan-Aman Town, 2013

\begin{tabular}{|c|c|c|c|c|}
\hline \multirow[t]{2}{*}{ Parasite species } & \multicolumn{4}{|c|}{ Infection intensity } \\
\hline & Light n(\%) & Moderate n(\%) & Heavy n(\%) & Mean egg count (epg) \\
\hline S. mansoni $(n=206)$ & $72(35)$ & $125(60.7)$ & $9(4.4)$ & $175 \pm 107$ \\
\hline A. lumbricoides $(n=132)$ & $76(57.6)$ & $49(37.1)$ & $7(5.3)$ & $15,263 \pm 1,9857$ \\
\hline T. trichiura $(n=86)$ & $32(37.2)$ & $51(59.3)$ & $3(3.5)$ & $3295 \pm 4163$ \\
\hline
\end{tabular}

epg eggs per gram 
Table 4 Predicators of intestinal parasitic infections among the school children $(n=460)$ in Mizan-Aman Town, 2013

\begin{tabular}{|c|c|c|c|c|c|}
\hline \multirow[t]{2}{*}{ Variables } & & \multicolumn{2}{|c|}{ Intestinal parasite } & \multirow[t]{2}{*}{ COR $(95 \% \mathrm{Cl})$} & \multirow[t]{2}{*}{ AOR $(95 \% \mathrm{Cl})$} \\
\hline & & Positive n(\%) & Negative $n(\%)$ & & \\
\hline \multirow[t]{2}{*}{ Age group in years } & $5-9$ & $242(82.0)$ & $53(18.0)$ & $2.2(1.430-3.451)^{*}$ & $2.6(1.552-4.298)^{*}$ \\
\hline & $\geq 10$ & $111(67.3)$ & $54(32.7)$ & 1 & 1 \\
\hline \multirow[t]{2}{*}{ Gender } & Male & $190(83.3)$ & $38(16.7)$ & $2.1(1.353-3.312)^{*}$ & $2.1(1.222-3.526)^{*}$ \\
\hline & Female & $163(70.2)$ & $69(29.8)$ & 1 & 1 \\
\hline \multirow[t]{2}{*}{ Type of school } & Public & $336(81.6)$ & $76(18.4)$ & $0.1(0.065-0.236)^{*}$ & $0.1(0.060-0.256)^{*}$ \\
\hline & Private & $17(35.4)$ & $31(64.6)$ & 1 & 1 \\
\hline \multirow[t]{2}{*}{ Source of water } & Well/river & $54(90.0)$ & $6(10)$ & $3.0(1.270-7.279) *$ & $2.4(0.912-6.191)^{*}$ \\
\hline & Tap & $299(74.8)$ & $101(25.2)$ & 1 & 1 \\
\hline \multirow[t]{2}{*}{ Eating raw vegetables } & Yes & $196(85.6)$ & $33(14.4)$ & $2.8(1.766-4.438)^{*}$ & $2.7(1.594-4.540)^{*}$ \\
\hline & No & $157(68)$ & $74(32)$ & 1 & 1 \\
\hline \multirow[t]{2}{*}{ Consumption of street foods } & Yes & $224(82.1)$ & 49 (17.9) & $2.1(1.327-3.184)^{*}$ & $2.3(1.341-3.813)^{*}$ \\
\hline & No & $129(69)$ & $58(31)$ & 1 & 1 \\
\hline \multirow[t]{2}{*}{ Latrine availability at home } & Yes & $319(77.2)$ & $94(22.8)$ & 1 & 1 \\
\hline & No & $34(72.3)$ & $13(27.7)$ & $0.7(0.391-1.520)$ & $1.3(0.548-3.010)$ \\
\hline \multirow[t]{2}{*}{ Hand washing before meal } & Always & $229(72.5)$ & $87(27.5)$ & 1 & 1 \\
\hline & Sometimes & $124(86.1)$ & $20(13.9)$ & $0.4(0.249-0.723)^{*}$ & $0.5(0.254-0.865)^{*}$ \\
\hline
\end{tabular}

COR crude odds ratio, $A O R$ adjusted odds ratio, $C l$ confidence interval

* Statistically significant at $P<0.05$

children were associated with IPIs. Deworming of the school children following WHO guideline is urgently required. Prevention of reinfection post-deworming of the school children, and monitoring of the interventions would be vital to reduce the burden of IPIs among the school children. The health extension program and school-parent forums should emphasize on school-health.

\section{Competing interests}

The authors declare that they have no competing interests.

\section{Authors' contributions}

AJ conceived, designed and drafted the manuscript. YA and ZM involved in data acquisition and analysis. EZ involved in data analysis and critically reviewed the manuscript. All authors contributed to the writing of the manuscript and approved the submitted version.

\section{Acknowledgements}

We thank Mizan-Tepi University for the financial support. We are grateful to Mr. Zenawi Kiflay, who co-ordinated the data acquisition. We acknowledge the study participants and administration of the schools.

\section{Author details}

${ }^{1}$ Department of Biomedical Science, College of Health Sciences, Mizan-Tepi University, Mizan, Ethiopia. ${ }^{2}$ Department of Medical Laboratory Sciences and Pathology, College of Health Sciences, Jimma University, Jimma, Ethiopia.

Received: 31 October 2014 Accepted: 19 June 2015

Published online: 02 July 2015

\section{References}

1. Pullan RL, Smith JL, Jasrasaria R, Brooker SJ. Global numbers of infection and disease burden of soil transmitted helminth infections in 2010. Parasit Vectors. 2014;7:37
2. Steinmann $\mathrm{P}$, Keiser J, Bos R, Tanner M, Utzinger J. Schistosomiasis and water resources development: systematic review, meta-analysis, and estimates of people at risk. Lancet Infect Dis. 2006;6:411-25.

3. Walter T. Effect of iron-deficiency anemia on cognitive skills and neuromaturation in infancy and childhood. Food Nutr Bull. 2003;24:S104-10.

4. Ezeamama AE, Friedman JF, Acosta LP, Bellinger DC, Langdon GC, Manalo DL, Olveda RM, Kurtis JD, Mcgarvey ST. Helminth infection and cognitive impairment among Filipino children. Am J Trop Med Hyg. 2005;72:540-8.

5. Mbuh JV, Nembu NE. Malnutrition and intestinal helminth infections in schoolchildren from Dibanda, Cameroon. J Helminthol. 2013;87:46-51.

6. Gutierrez-Jimenez J, Torres-Sanchez MG, Fajardo-Martinez LP, Schlie-Guzman MA, Luna-Cazares LM, Gonzalez-Esquinca AR, Guerrero-Fuentes S, Vidal JE. Malnutrition and the presence of intestinal parasites in children from the poorest municipalities of Mexico. J Infect Dev Ctries. 2013;7:741-7.

7. Hotez PJ, Fenwick A, Savioli L, Molyneux DH. Rescuing the bottom billion through control of neglected tropical diseases. Lancet. 2009;373:1570-75.

8. Nacher M, Singhasivanon P, Silachamroon U, Treeprasertsu S, Krudsood S, Gay F, Mazier D, Looareesuwan S. Association of helminth infections with increased gametocyte carriage during mild falciparum malaria in Thailand. Am J Trop Med Hyg. 2001;65:644-7.

9. Degarege A, Erko B. Association between intestinal helminth infections and underweight among school children in Tikur Wuha Elementary School, Northwestern Ethiopia. J Infect Public Health. 2013;6:125-33.

10. Alderman H, Konde-Lule J, Sebuliba I, Bundy D, Hall A. Effect on weight gain of routinely giving albendazole to preschool children during child health days in Uganda: cluster randomised controlled trial. BMJ. 2006:333:122

11. World Health Organization. Helminth control in school-age children: a guide for managers of control program. 2nd ed. Geneva: WHO; 2011.

12. Mathewos B, Alemu A, Woldeyohannes D, Alemu A, Addis Z, Tiruneh M, Aimero 297 M, Kassu A. Current status of soil transmitted helminths and Schistosoma mansoni infection among children in two primary schools in North Gondar, Northwest Ethiopia: a cross sectional study. BMC Res Notes. 2014;7:88

13. Alemu A, Atnafu A, Addis Z, Shiferaw Y, Teklu T, Mathewos B, Birhan W, Gebretsadik S, Gelaw B. Soil transmitted helminths and Schistosoma mansoni infections among school children in Zarima town, northwest Ethiopia. BMC Infect Dis. 2011;11:189. 
14. Awoke W, Muche S. A cross sectional study: latrine coverage and associated factors among rural communities in the District of Bahir Dar Zuria, Ethiopia. BMC Public Health. 2013;13:99.

15. Abossie A, Seid M. Assessment of the prevalence of intestinal parasitosis and associated risk factors among primary school children in Chencha town, Southern Ethiopia. BMC Public Health. 2014;14:166.

16. Legesse M, Erko B. Prevalence of intestinal parasites among schoolchildren in a rural area close to the southeast of Lake Langano, Ethiopia. Ethiop J Health Dev. 2004;18:116-20.

17. Cheesbrough M. District Laboratory Practice in Tropical Countries, Part I. 2nd ed. Cambridge: Cambridge University Press; 2009. p. 196-8.

18. World Health Organization. Eliminating soil-transmitted Helminthiases as a public health problem in children: progress report 2001-2010 and strategic plan 2011-2020. Geneva: WHO; 2012.

19. World Health Organization. Prevention and control of schistosomiasis and soil-transmitted helminthiasis, Technical report series. Geneva: WHO; 2002.

20. Fentie T, Erqou S, Gedefaw M, Desta A. Epidemiology of human fascioliasis and intestinal parasitosis among schoolchildren in Lake Tana Basin, northwest Ethiopia. Trans R Soc Trop Med Hyg. 2013;107:480-6.

21. Tulu B, Taye S, Amsalu E. Prevalence and its associated risk factors of intestinal parasitic infections among Yadot primary school children of Southeastern Ethiopia: a cross-sectional study. BMC Res Notes. 2014;7:848.

22. Yami A, Mamo Y, Kebede S. Prevalence and predictors of intestinal helminthiasis among school children in Jimma zone; a cross-sectional study. Ethiop J Health Sci. 2011;21:167-74.

23. Amare B, Ali J, Moges B, Yismaw G, Belyhun Y, Gebretsadik S, Woldeyohannes 329 D, Tafess K, Abate E, Endris M, Tegabu D, Mulu A, Ota F, Fantahun B, Kassu A. Nutritional status, intestinal parasite infection and allergy among school children in northwest Ethiopia. BMC Pediatr. 2013;13:7.

24. Worku L, Damte D, Endris M, Tesfa H, Aemero M. Schistosoma mansoni Infection and Associated Determinant Factors among School Children in Sanja Town, Northwest Ethiopia. J Parasitol Res. 2014;2014:792536.

25. Alebie G, Erko B, Aemero M, Petros B. Epidemiological study on Schistosoma mansoni infection in Sanja area, Amhara region, Ethiopia. Parasit Vectors. 2014;7:15.

26. Mitiku H, Legesse M, Teklemariam Z, Erko B. Transmission of Schistosoma mansoni in Tikur Wuha area, Southern Ethiopia. Ethiop J Health Dev. 2010;24:180-4.

27. Tefera T, Biruksew A, Mekonnen Z, Eshetu T. Parasitic contamination of fruits and vegetables collected from selected local markets of Jimma Town, Southwest Ethiopia. ISRN. 2014;2014:Article ID 382715.

28. Wani SA, Ahmad F, Zargar SA, Ahmad Z, Ahmad P, Tak H. Prevalence of intestinal parasites and associated risk factors among schoolchildren in Srinagar City, Kashmir, India. J Parasitol. 2007;93:1541-3.

29. Kattula D, Sarkar R, Rao Ajjampur SS, Minz S, Levecke B, Muliyil J, Kang G. Prevalence \& risk factors for soil transmitted helminth infection among school children in south India. Indian J Med Res. 2014;139:76-82.

30. Quihui L, Valencia ME, Crompton DWT, Phillips S, Hagan P, Morales G, Díaz-Camacho SP. Role of the employment status and education of mothers in the prevalence of intestinal parasitic infections in Mexican rura schoolchildren. BMC Public Health. 2006;6:225.

31. Hotez PJ, Brooker S, Bethony JM, Bottazzi ME, Loukas A, Xiao S. Hookworm Infection. N Engl J Med. 2004;351:799-807

\section{Submit your next manuscript to BioMed Central and take full advantage of:}

- Convenient online submission

- Thorough peer review

- No space constraints or color figure charges

- Immediate publication on acceptance

- Inclusion in PubMed, CAS, Scopus and Google Scholar

- Research which is freely available for redistribution

Submit your manuscript at www.biomedcentral.com/submit 